\title{
Prevention of Grievances through AB-NHPM Policy Document Amendments (AB-NHPM: Ayushman Bharat-National Health Protection Mission)
}

\section{Mannuru $\mathbf{M}^{*}$}

Punjab Health Systems Corporation, State Institute of Health and Family Welfare, Government of Punjab, Chandigarh, India

*Corresponding author: Manjuram Mannuru, Punjab Health Systems Corporation, State Institute of Health and Family Welfare, Government of Punjab, Chandigarh, India, Tel: +919010430722; E-mail: mannurumanjuram@gmail.com

Received date: November 8, 2018; Accepted date: November 26, 2018; Published date: November 30, 2018

Copyright: $\odot 2018$ Mannuru M. This is an open-access article distributed under the terms of the Creative Commons Attribution License, which permits unrestricted use, distribution, and reproduction in any medium, provided the original author and source are credited.

\begin{abstract}
Background: The NHPM is a central initiative targeting approximately $50 \mathrm{Cr}$ deprived population of the country. When beneficiaries seek service from the providers, there is a chance for the raise of grievances. Whenever, a beneficiary faces any difficulty, it needs to be redressed through a dedicated system which is specially placed for this function, but efficient system will never wait for the grievances to arise but prevents it either at the stage of policy designing or implementation phase. Due to this reason, there is a need to study each clause of the policy document, and to know how it works during utilization by the policyholders.
\end{abstract}

Objective: To identify the clauses in the 'Model Tender Document.volume.2 for Selection of Implementation Support Agency for providing support services for the implementation of AB-NHPM' which could be of concern to the stakeholders of the scheme?

Methods: Secondary data analysis of newspapers, previous studies, and IRDAl's regulatory documents for literature review. Results were obtained through review of 'Model Tender Document.volume.2 for Selection of Implementation Support Agency for providing support services for the implementation of AB-NHPM'.

Observations: The clauses related to pre-existing conditions, exclusions, emergency conditions and Community Health Centre $(\mathrm{CHC})$ hospitals could be of concern to the stakeholders in the scheme and affect overall quality of the scheme.

Conclusion: Firstly, although pre-existing diseases are covered, mostly people with chronic diseases require Out Patient Department (OPD) consultation, but OPD is excluded under this Scheme. Secondly, the clauses related to exclusions require clarification whether diseases related to alcohol, drugs and tobacco will be entertained or not because insurance companies are reluctant to cover. Thirdly, a few conditions related to emergency should be relaxed to the private hospitals in order to improve accessibility. Lastly, the CHCs hospitals will face difficulty in maintenance of MIS, resultant there could be problems with medical audit under the scheme.

Keywords: Grievances; Public health insurance; Policy amendments; Medical claims; Emergency consultation;

Abbreviations: AB: Ayushman Bharat; NHPM: National Health Protection Mission; SHA: State Health Agency; ISA: Implementation Support Agency; RSBY: Rashtriya Swasthya Bima Yojna; IRDA: Insurance Regulatory and Development Authority; MTD: Model Tender Document; CHC: Community Health Centre; OPD: Out Patient Department; MIS: Management of Information System

\section{Background}

The Ayushman Bharat ( $\mathrm{AB}$ herein), a recent initiative announced by Central Finance Minister during budget session in the Parliament, has two components:

- Health \& Wellness Centers, and

- National Health Protection Mission (NHPM herein).
The scheme will cover 11.22 Cr eligible families as per SECC 2011 data under deprived category, and this number will be approximately $50 \mathrm{Cr}$ beneficiaries [1,2]. This is approximately $37.0 \%$ of present total population of India.

AB-NHPM is a public health insurance scheme, the source of finance is from Govt. revenue, financing agent is insurance Company, service providers are hospitals, and consumers are policy holders. The scheme has been structured as National Health Agency (NHA herein) at Central level, helps in designing policy and providing financial support. State Health Agency (SHA herein) at State Level, implements the scheme either to set up Trust Model or Insurance Model. In Insurance model the Implementation Support Agency/Insurance Company (ISA herein) will support for implementation of the scheme through tripartite agreement (between SHA and ISA along with Service providers) [3].

When beneficiaries seek service from the providers, there is a chance for the raise of grievances. A "Grievance/Complaint" means written expression (includes communication in the form of electronic 
mail or other electronic scripts), of dissatisfaction by a complainant with insurer, distribution channels, intermediaries, insurance intermediaries or other regulated entities about an action or lack of action about the standard of service or deficiency of service of such insurer, distribution channels, intermediaries, insurance intermediaries or other regulated entities [4]. The grievances can arise from charging money while seeking services, charging over the package rates, delay in authorizations, enrolment issues and claims repudiations and delay of claim settlement, suspension of hospitals, and even Implementation Support Agency (ISA) may face issues related to delay of premium payment by State Health Agency (SHA) or medical audit/hospital audit etc.

Below, a few past experiences were mentioned about the concerns faced by the beneficiaries and hospitals under the public health insurance schemes in India.

In July $5^{\text {th }}, 2010$, The Hindu News Paper reported as "Medical College hospitals bogged down by Rashtriya Swasthya Bima Yojna (RSBY)" about the Government Medical College in Thiruvananthapuram [5]. The hospital said to the media that "In the past seven months hospital has treated 2049 patients under Rashtriya Swasthya Bima Yojna (RSBY) and total claims amount was made Rs. 1.183 crore, while the actual expenditure is about Rs. 96 Lakhs. But the hospital has received only about Rs.71 lakhs of its claims and it would be months before the rest of the payments come in". This was one of the frequent concerns faced by network hospitals under government sponsored health insurance schemes and if this debt reaches high, then hospitals eventually deny the treatments.

In Kerala, "Rejection of medical claims under RSBY alleged" $\left(09^{\text {th }}\right.$ April, 2015) reported by The Hindu News Paper there were many beneficiaries left hospital without completing their treatment after the Insurance company rejected their claims [6]. Mr. G. Sukumaran (Professor of Medicine, Pushpagiri Medical College, Thiruvallur) said $80 \%$ of the patients admitted to the medical ward in the hospital were denied their insurance claim on flimsy grounds. He also said that a patient named Mr. Thankappan Chettiar $\left(\begin{array}{lll}60 & \mathrm{y} & \text { old }\end{array}\right)$ from Avaneeswaran in Kollam district was admitted to the hospital with upper oesophageal dysphagia on March 30 and it took $24 \mathrm{~h}$ for making a definite diagnosis. Insurance company rejected his claim saying that a definite diagnosis should have been made within 24 hours of his hospitalization.

Another issue of public health insurance schemes, which was related to Punjab Employees Health Insurance Scheme', reported as "Punjab health plan beneficiaries in lurch" $\left(09^{\text {th }}\right.$ March 2017$)$ by "The Tribune" News Paper [7]. A large number of beneficiaries' claims were rejected by the Insurance Co. due to the reason of delay in submission of their claims. As per the policy terms, the insurer has to consider all those claims received within one month from the date of discharge from hospital. Since, the scheme policy was ended on $31^{\text {st }}$ December 2016; Insurance Company has denied entertaining the claims which were submitting after $31^{\text {st }}$ January 2017.

These kinds of issues leads to consumer's dissatisfaction and lead to complaints. When many consumers complain against the similar products or services, it is an indicative of quality of those products or services. Malhotra et al. used to measure the quality of the insurance products based on the complaints rate for their study [8]. Hence, the policyholders or beneficiaries interests need to be protected through placing a Grievance Redressal Mechanism under the Insurance Schemes. Further, It is a legal requirement under clause 17 of the
Insurance Regulatory and Development Authority (IRDA) (Protection of Policyholders' Interests) Regulations, 2017 [4].

However, effective policies will never wait for the grievance but prevents it before they arise. Policy designing phase could be an opportunity to do this. Moreover, preventing grievances through policy amendments will not only satisfy the beneficiary but also improves the quality of the AB-NHPM scheme. Due to this reason, there is a need to study each clause of the policy document, and to know later how it works during utilization by the policyholders. Hence, this article will be discussed about 4 policy issues in the Model Tender Document Volume.2 (MTD herein) which would prevent grievances before they arise through policy amendments and will give suggestions to improve the quality of the scheme [3].

\section{Objective}

To identify the clauses in the 'Model Tender Document.volume.2 for Selection of Implementation Support Agency for providing support services for the implementation of AB-NHPM' which could be of concern to the stakeholders of the scheme?

\section{Methodology}

Secondary data analysis of newspapers, previous studies on insurance, and Insurance Regulatory and Development Authority of India's (IRDAI herein) regulatory documents related to Insurance for literature review. The study results were obtained through review of 'Model Tender Document.volume.2 for Selection of Implementation Support Agency for providing support services for the implementation of AB-NHPM. The MTD is available in the scheme official website for suggestions. This analysis is applicable for State/UT Governments that have opted for this Insurance model.

\section{Observations}

The following clauses of Model Tender Document-MTD have been identified that could lead to arousal of grievances:

- The MTD 5.2.a clause that covers pre-existing conditions.

- The MTD exclusions are listed in annexure 2.2. The conditions do not require hospitalization or treated under OPD, diagnostic or evaluator procedures unless pre or post hospitalization treatment, dental care without external injury, congenital diseases, sex change or hormone therapy, vaccination, suicide or intentional injury and persistent vegetative state.

- The MTD section 5.3.b mentioned about the benefits under the AB-NHPM Cover shall, subject to the available AB-NHPM Sum Insured, be available to the AB-NHPM Beneficiary on a cashless basis at any EHCP (Empanelled Health Care Provider herein).

- MTD annexure 2.2 (Specialty category 22 emergency room package less than $12 \mathrm{~h}$.) without pre authorization the service is available. Emergency consultation: Acute colic, high fever, cut, stitches, soft tissue injury, FB removal and Single bone fracture plaster, nebulization for asthmatic attack, moderate dehydration, hypoglycaemia in a diabetic, Dengue without complication, Syncope, Food poisoning etc. are available only in Public sector facilities.

- Section 4.2 of the MTD mentioned about new family member can be added after due approval of Government.

- The clause $15 . b$ of the MTD mentioned about the claims management. As per this provision all the claims shall be settled 
within 15 days from the date of submission of last required document

\section{Discussion}

\section{The proposed AB-NHPM shall cover all the pre-existing conditions from the day one}

[The IRDA definition of pre-existing condition/disease is "a medical condition/disease that existed before you obtained health insurance policy, within 48 months of prior to the $1^{\text {st }}$ policy". Generally the insurance companies do not cover such pre-existing conditions].

The MTD 5.2.a clause states that pre-existing conditions are covered by the policy. This clause allows chronic conditions also to be covered. All the chronic conditions may not require hospitalization but OPD treatment is enough. Contrary to this, OPD treatment is excluded as per the annexure 2.2 in the MTD. An example: The MTD Annexure 2.3, Specialty 8, package no 155-'chronic prostatitis-Package for evaluation/investigation (ultrasound + culture + prostate massage) for 1 month (medicines) and follow up visit once in 3 months' was allowed. But this is treated mostly under OPD.

Some diseases require temporary or permanent care for over the period, hence the care mostly involved with medical consultation, periodic health check-up, medicines which are daily administration. Another example of age related eye disorders like macular degeneration required Avastin/Lucentis injection which costs approximately $\$ 55$ to $\$ 2000$ per dose and requires with frequency of a month to six months once.

Suggestion: For chronic diseases Out Patient Department (OPD) consultation should be allowed with medicines and injections. It will potentially reduce the grievances and denial of treatments.

Another important factor, mostly senior citizens are affected by chronic diseases, so allowing Out Patient Department (OPD) consultation for Senior Citizens and Disabled people will bring more equity in the scheme.

\section{Exclusions under scheme}

It is ethical to consider each claim to pay when a premium is charged form the beneficiary and the denial of claim means the denial of treatment. Since, Insurance is a profit making business, so it is necessary to exclude some conditions in order to protect the other policy holders' interest, the Insurer sustainability, for expansion of its activities/business and to control the costs or moral hazard (over utilization). In this hypothetical situation what we need to understand that "In the group policy or public health Insurance schemes the Insurer doesn't have either a choice to underwrite (selection of risk based on health or living standards to decide premium) or feasible to underwrite, and at the same time even the policy holders doesn't have an Insurable interest. So, it is necessary to exclude a few diseases/ conditions.

The MTD exclusions clauses listed in annexure 2.2 has conditions that do not require hospitalization or treated under OPD, diagnostic or evaluator procedures unless pre or post hospitalization treatment, dental care without external injury, congenital diseases, sex change or hormone therapy, vaccination, suicide or intentional injury and persistent vegetative state. The MTD exclusion clause doesn't mention about the conditions having a history of alcohol/smoking/drugs. But, the Insurance companies will reject the claims under standard IRDA exclusions clause. Hence, a large number of repudiated claims will be possible to arise if not cleared.

Suggestion: The MTD document should be clear about either the diseases related to and persons having history of alcohol/tobacco/ drugs are excluded to pay claim or provide services. It should be covered because, the Government issues legal permit to sell alcohol/ tobacco or fail to control alcohol/tobacco/drugs.

\section{Emergency conditions}

Treating at emergency ward doesn't imply that the condition was an emergency and patient perceived emergency will not be taken into account unless there was a threat to life confirmed by the doctor. Example: Seizures, most of the conditions will be treated in emergency room and most of them discharge before $24 \mathrm{~h}$. Hence, the claim will be rejected under OPD treatment. This has been taken care by the MTD annexure 2.2 (category 22 emergency room package less than $12 \mathrm{~h}$ without pre authorization the service is available.

But, Emergency consultation: acute colic, high fever, cut, stitches, soft tissue injury, FB removal and Single bone fracture plaster, nebulization for asthmatic attack, moderate dehydration, hypoglycaemia in a diabetic, Dengue without complication, Syncope, Food poisoning etc. are available only in the public sector facilities. At times accessibility of public facilities will be difficult for beneficiaries due to geographical inequality and urban centric healthcare facilities existing across the country. Further, The MTD section 5.3.b mentions about the benefits under the AB-NHPM Cover shall, subject to the available AB-NHPM Sum Insured, is available to the AB-NHPM Beneficiary on a cashless basis at any EHCP (Empanelled Health Care Provider). But, In case of emergency the patient must go to nearest hospital because they might not have time to check whether the hospital is empanelled or not.

Suggestion: For the convenience "the AB-NHPM beneficiary can visit any nearest hospital irrespective of EHCP and the benefit should be available under reimbursement basis" for non-empanelled hospitals.

The annexure 2.2 (Specialty category 22 ( $2 \& 3$ ) emergency room package less than $12 \mathrm{~h}$ ) should be relaxed to private facilities too.

\section{CHC hospitals}

The clause $15 . \mathrm{b}$ of the MTD mentions about the claims management. As per this provision the ISA shall be responsible for settling all claims within 15 days after receiving all the required information/ document. Also for medical audit the capacity of Community Health Centre (CHC) hospitals in maintaining medical records or Management of Information System (MIS herein) is limited. So, there will be a chance of denial of claims or pendency may increase for CHCs by insurance companies saying that the documents are not fit for audit.

Suggestion: This provision should be "There shall not be any delay in claim settlement for any reason to the public hospitals" or alternatively reconciliation of those claims with monthly review meetings would resolve grievances at initial stage. However, this would not be recommended in long term but the capacity building of $\mathrm{CHCs}$ in maintenance of MIS is necessary. 
Citation: Mannuru M (2018) Prevention of Grievances through AB-NHPM Policy Document Amendments (AB-NHPM: Ayushman Bharat-National Health Protection Mission). Health Econ Outcome Res Open Access 4: 158. doi:10.4172/2471-268X.1000158

Page 4 of 4

\section{Conclusion}

When multiple stakeholders are involved in AB-NHPM then the consumer interests need to be protected while seeking services. So, setting up of grievance redressal system in place is not only legal requirement under IRDA (Protection of Policyholder's) Regulations 2002 but also improves quality of the scheme. The efficient grievance redressal system does not wait for grievances to arise but prevents them. This study identified a few clauses which should be amended in order to improve the accessibility of the scheme.

Although pre-existing diseases are allowed; under this mostly people with chronic diseases require Out Patient Department (OPD) consultation, but OPD excluded under policy. Further, the policy document is not clear about the IRDA standard exclusions related to alcohol, drugs and tobacco that's where a large repudiation of claims occurs. Furthermore, a few conditions related to emergency should be relaxed to the private hospitals in order to improve accessibility. Lastly, the CHCs hospitals will face difficulty in maintenance of MIS, which could lead to problems during hospital audit under the scheme.

\section{Study Limitations}

This study is applicable to the State/UT governments which are opted for Insurance model for implementation of AB-NHPM. The nomenclature of the scheme was frequently changed from earlier NHPS (National Health Protection Scheme) to PMRSSM (Pradhan Mantri Rashtriya Swasthya Suraksha Mission) then to AB-NHPM (Ayushman Bharat-National Health Protection Mission) and now to the current name PM-JAY (Pradhan Mantri-Jan Arogya Yojana).

\section{Significance of this Study}

This study reviewed the Model Tender Document, Volume 2 of the AB-NHPM and suggested possible policy amendments to prevent grievances in order to improve overall quality of the scheme. In insurance, the quality of the product is measured through the rate of complaints, hence reducing the grievances means improving the quality [8-12].

\section{Summary of Findings}

Pre-existing diseases is covered under the AB-NHPM but policy holders won't be able access certain services, due to OPD is under
Exclusion because most of these diseases require OPD consultation and periodic health check-ups.

The MTD exclusions clause require clarification related to the diseases having history of alcohol, drugs and tobacco which insurance companies do not entertain.

During emergency patient should be relaxed to any nearest hospital, irrespective of whether it is empanelled or not in order to improve accessibility of the AB-NHPM.

Capacity of CHCs for maintenance of MIS will be another challenging issue. This will either delay or even deny the claims by insurance companies saying patient medical file is not fit for audit.

\section{References}

1. https://www.thehindu.com/business/budget/budget-2018-jaitleyannounces-worlds-largest-healthcare-programme/article22618631.ece

2. http://pib.nic.in/newsite/PrintRelease.aspx?relid=176049

3. Model tender document for selection of implementation support agency for providing support services for the implementation of Ayushman Bharat - National Health Protection Mission (2018) National Health Agency, Ministry of Health and Family Welfare, Government of India.

4. http://www.policyholder.gov.in/uploads/CEDocuments/PPHI-2017.pdf

5. https://www.thehindu.com/news/cities/Thiruvananthapuram/Medicalcollege-hospitals-bogged-down-by-RSBY/article16185942.ece

6. https://www.thehindu.com/news/national/kerala/rejection-of-medicalclaims-under-rsby alleged/article7083630.ece

7. https://www.tribuneindia.com/news/punjab/community/punjab-healthplan-beneficiaries-in lurch/374932.ht

8. https://www.nipfp.org.in/media/medialibrary/2018/05/WP_228.pdf

9. https://indianexpress.com/article/cities/chandigarh/pgi-denies-rsbybenefits-to-poor-patients/

10. Doerpinghaus, Doerpinghaus B, Nelson A, Oztaysi, Ubl (2010) Use the complaints rate to measure quality of insurance products like auto insurance and life insurance.

11. http://www.policyholder.gov.in/uploads/CEDocuments/Health \%20Insurance\%20Regulations\%202016.pdf

12. https://economictimes.indiatimes.com/wealth/insure/ayushman-bharathow-to-check-entitlement-and-eligibility/articleshow/65422257.cms 